Design and Effects of the Proton Window of the Spallation Neutron Source

\author{
Felix C. Difilippo \\ Oak Ridge National Laboratory \\ P.O. Box 2008 \\ Oak Ridge, TN 37831-6363 \\ USA \\ Paper to be Presented and Published \\ In the Proceedings \\ Of the International Conference on \\ Advanced Monte Carlo for Radiation Physics, \\ Particle Transport Simulations and \\ Applications \\ Organized by \\ Instituto Tecnologico e Nuclear \\ Lisbon, Portugal \\ 23-26 October 2000.
}




\title{
Design and Effects of the Proton Window of the Spallation Neutron Source
}

Felix C. Difilippo

Oak Ridge National Laboratory

P.O. Box 2008 Oak Ridge, TN 37831-6363, USA

\begin{abstract}
Design parameters for the target region of the Spallation Neutron Source were calculated by following histories of $1 \mathrm{GeV}$ protons and their shower of particles with the Monte Carlo code MCNPX. In particular, neutron currents, radiation damages, doses and heat distributions for the target region of the facility along the path of the proton beam are presented from the point of view of the perturbation effects of the proton beam window.
\end{abstract}

\section{Introduction}

The Spallation Neutron Source project ${ }^{1}$ is a national effort, within the United States, to build a powerful pulsed neutron source at the Oak Ridge National Laboratory. The multidisciplinary endeavor requires the coordination of the research and development of several national laboratories that follows, more or less, a natural progression: ion source, acceleration, storage of the proton beam, target station and experimental area. Present parameters of the design are for a $2 \mathrm{~mA}$ current of $1 \mathrm{GeV}$ protons.

The target area is the part of the facility built around the $\mathrm{Hg}$ target that converts the proton beam into 18 neutron beams via the spallation reaction. It includes, beside the $\mathrm{Hg}$ target, ambient and cryogenic temperature moderators, beam tubes, shielding materials and associated coolant systems. Some key radiation transport parameters of the design are: neutron production, heating rates, radiation damage, doses and neutron currents in the experimental areas.

The physical boundary between the incoming proton beam and the target station is a semicircular inconel window, cooled with water, of approximately $8 \mathrm{~cm}$ height, $30 \mathrm{~cm}$ extent and $4 \mathrm{~mm}$ width (two $2 \mathrm{~mm}$ sections separated by $1.6 \mathrm{~mm}$ of cooling water). See figure 1 for details.

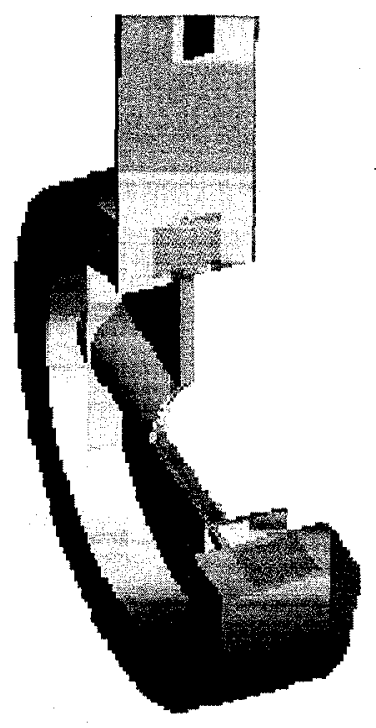

Figure 1: Cut of the inconel proton beam window of the Spallation Neutron Source showing the coolant. 
Although the width is very narrow, it affects the proton beam distribution and consequently the neutron, radiation damage and heat distributions in the vicinity of the direction of the beam. Since this is also the region of the $\mathrm{Hg}$ converter and its container that is subject to the most intense heat, it is important to know, not only the condition at the window region, but also the effects along the path of the beam. Figure 2 shows a view of the target station model along the path of the proton beam and in the vicinity of the window.

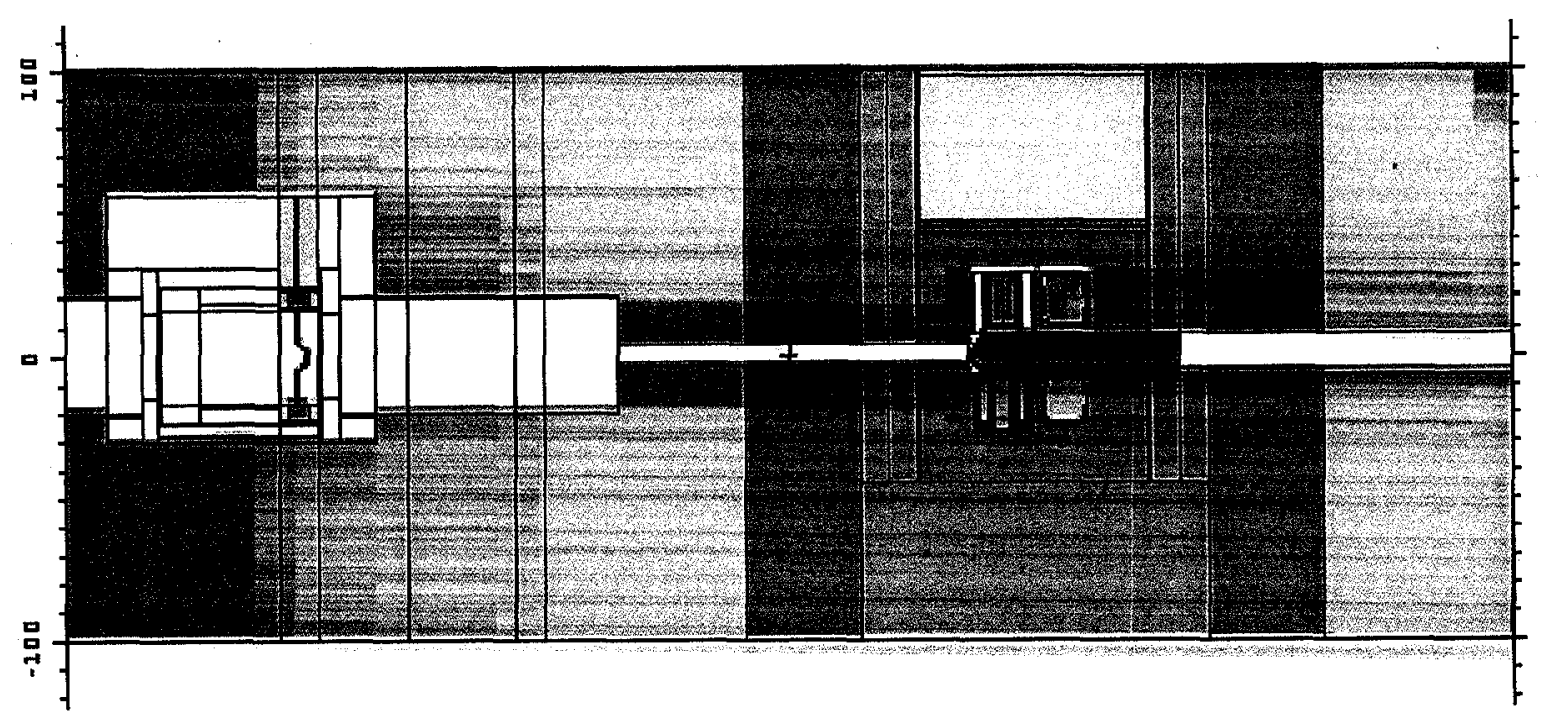

Figure 2: Cross section of the Spallation Neutron Source target station model along the proton beam. The left of the figure shows the location of the proton beam window and the box for beam diagnostics.

Detailed calculations of the design parameters are presented in the following sections. They were done by tracking the protons and their shower of particles with the Monte Carlo code MCNPX ${ }^{2}$, a synthesis of the hadronic code LAHET ${ }^{3,4}$ and MCNP $^{5}$.

\section{Interactions of the Proton Current with the Proton Window}

The boundary of the model is the Ring to Target Building Transport (RTBT) tunnel, thus the proton current coming through the beam path and colliding with the proton window is used as the external source of the model ${ }^{6}$. Particularly relevant for the design is the beam profile over the $\mathrm{Hg}$ target, shown in Figure 3 together with the profile of the unperturbed beam. The distributions, normalized to an incoming proton current of $2 \mathrm{~mA}$, show some spread with a substantial part $(94.4 \%$ ) of the beam impacting the $\mathrm{Hg}$ target. There is a shift of about $5 \mathrm{MeV}$, not shown here, in the proton spectra.

The window itself is the subject of intense heating and radiation damage. Detailed maps of these magnitudes are thus very important for the engineering details of the design. Our window is composed of two Inconel walls ( $2 \mathrm{~mm}$ each) separated by water coolant $1.6 \mathrm{~mm}$ thick. Two dimensional total heat distributions for the walls were computed for a total current of $2 \mathrm{~mA}$. There is a strong correlation of the heat density with the proton current density: $\mathrm{H}(\mathrm{w} / \mathrm{g})=2.185 \mathrm{~J}\left(\mu \mathrm{A} / \mathrm{cm}^{2}\right)$. Displacements per atom (dpa) of stainless steel atoms due to the protons were calculated with the proton flux and cross sections from Ref 7 and are shown in Figure 4. 


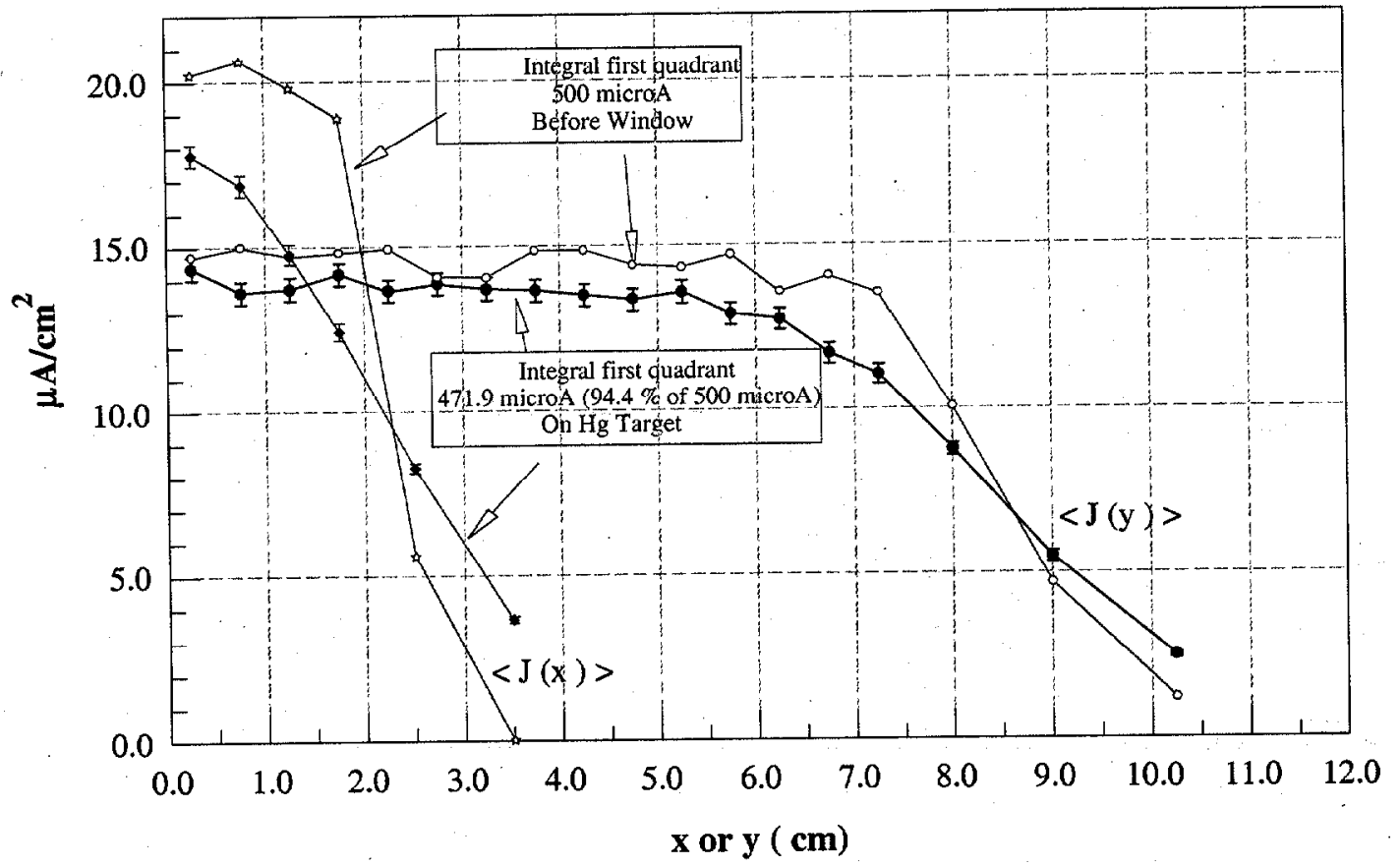

Figure 3: Proton current densities in front of the proton beam window and on the $\mathrm{Hg}$ target; average distributions in $\mathrm{x}$ (vertical) and $\mathrm{y}$ (horizontal).

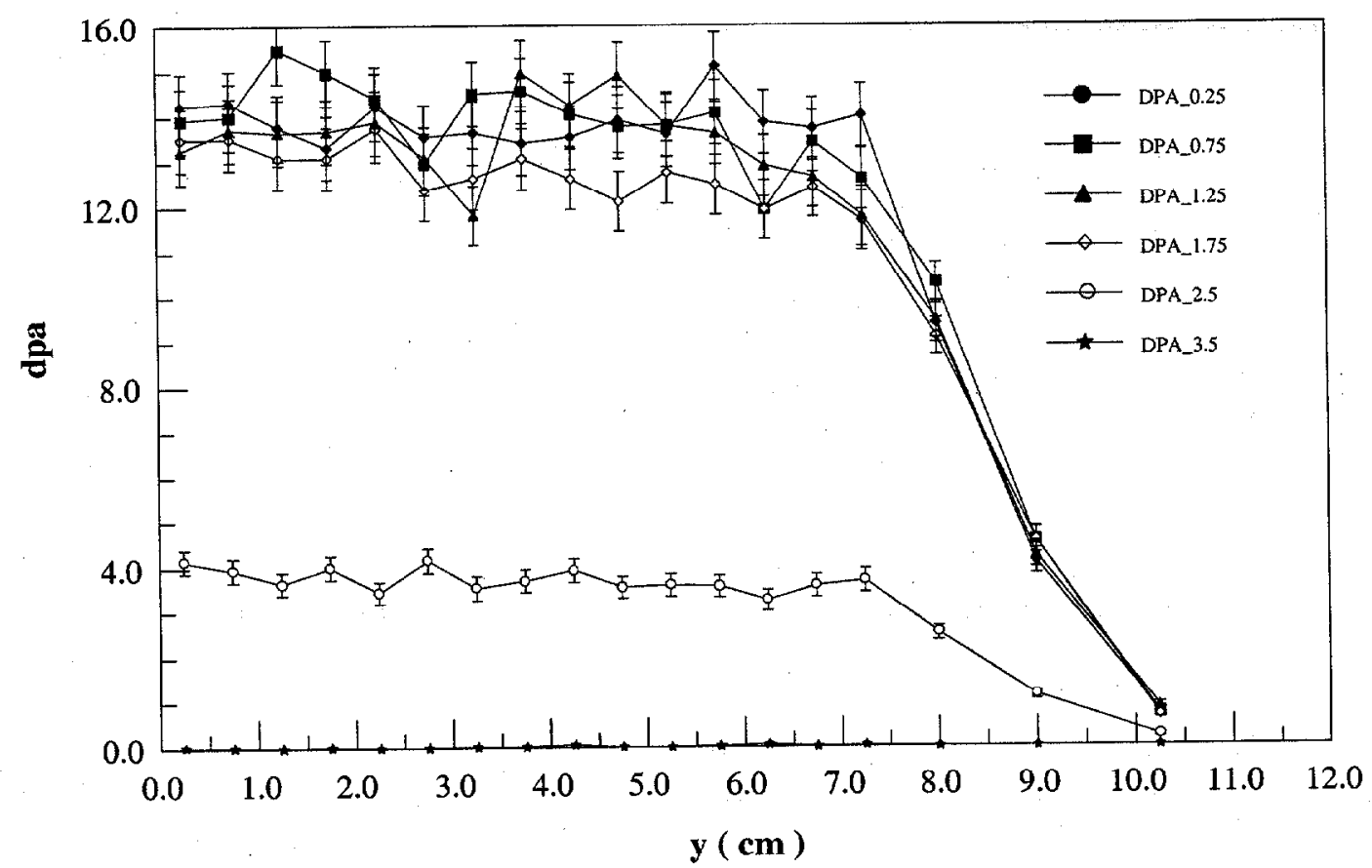

Figure 4: dpa (due to protons) for stainless steel in the proton beam window for 1 full year operation at $2 \mathrm{~mA}$. 


\section{Heating and Radiation Damage Along the Beam Path}

Table 1 summarizes the geometry of the beam path and the media around it. Tallies were defined for the material regions in rings along and around the beam path.

Table 1

Geometry and Material Regions Along the Beam Path

\begin{tabular}{|c|c|c|}
\hline Z (cm from center) & Geometry & Materials Around \\
\hline 22.5 to 144.4 & Rectangular duct $8 \times 22 \mathrm{~cm}$ & $\begin{array}{c}\text { Target and Inner (Be), Mid } \\
(\mathrm{Pb}) \text { and Outer (SS) } \\
\text { shielding plugs }\end{array}$ \\
\hline 144.4 to 228.6 & Circular Duct (16") & SS shielding plugs \\
\hline 228.6 to 321.2 & $\begin{array}{c}\text { Rectangular duct } \\
86.36 \times 60.96 \text { for beam } \\
\text { diagnostic box and proton } \\
\text { beam window }\end{array}$ & SS shielding plugs \\
\hline 321.2 to 506 & Circular Duct (16") & SS shielding plugs \\
\hline
\end{tabular}

Figure 5 shows the heating rates in $2 \mathrm{~cm}$ thick rings of material regions along the path of the beam. Neutron contributions are important only near the target and the local maximum of the heat occurs at the contractions of the material media along the beam path

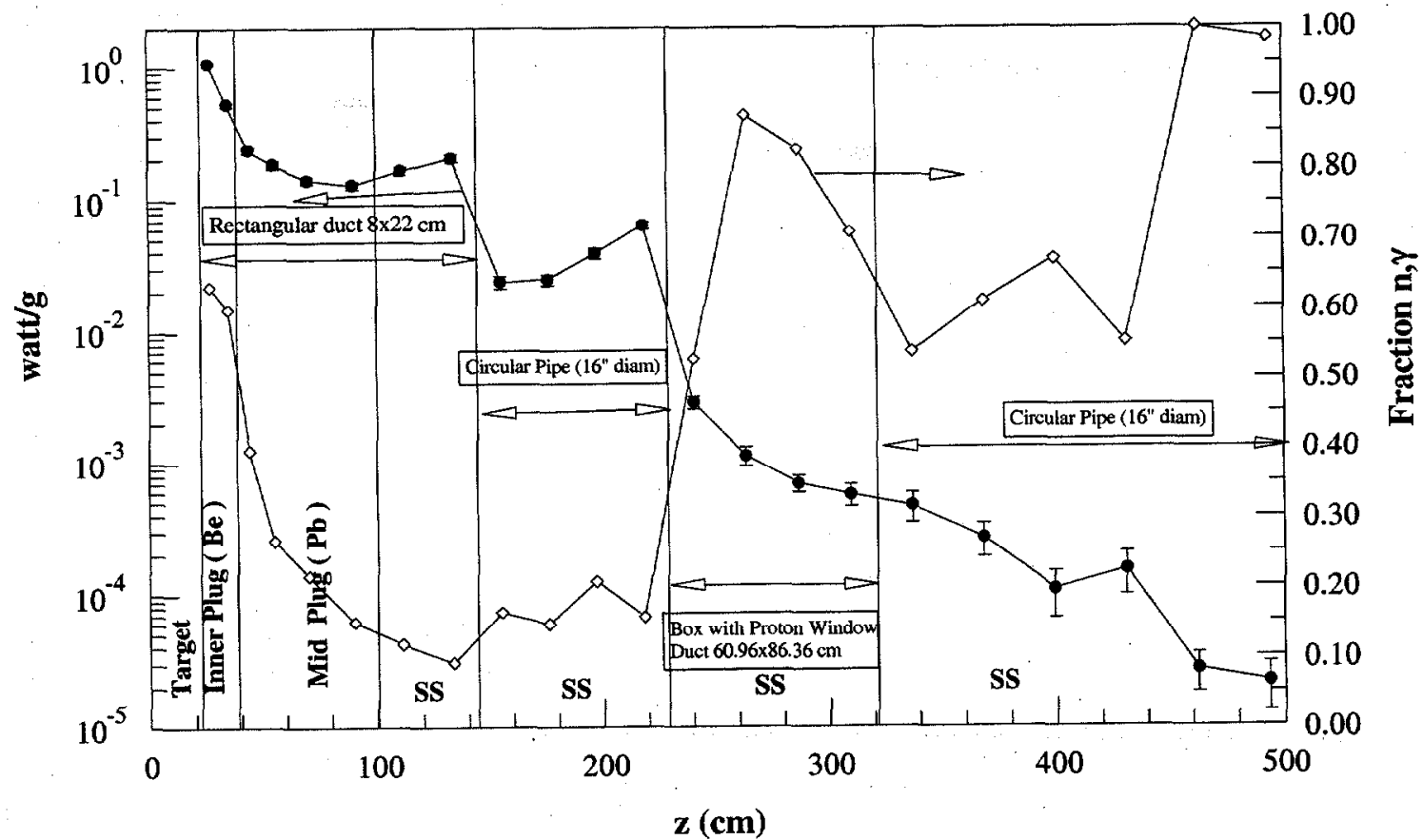

Figure 5: Total heating rate and $\mathrm{n}$ plus $\gamma$ heating fractions for $2 \mathrm{~cm}$ thick rings along the path of the beam. 
Total (neutron plus proton) dpa and the proton fraction are shown in Figure 6 for stainless steel ( 1 year at $2 \mathrm{~mA}$ ) located in $2 \mathrm{~cm}$ rings along the path of the beam, the proton contributions also have a local maximum at the contractions of the media along the path.

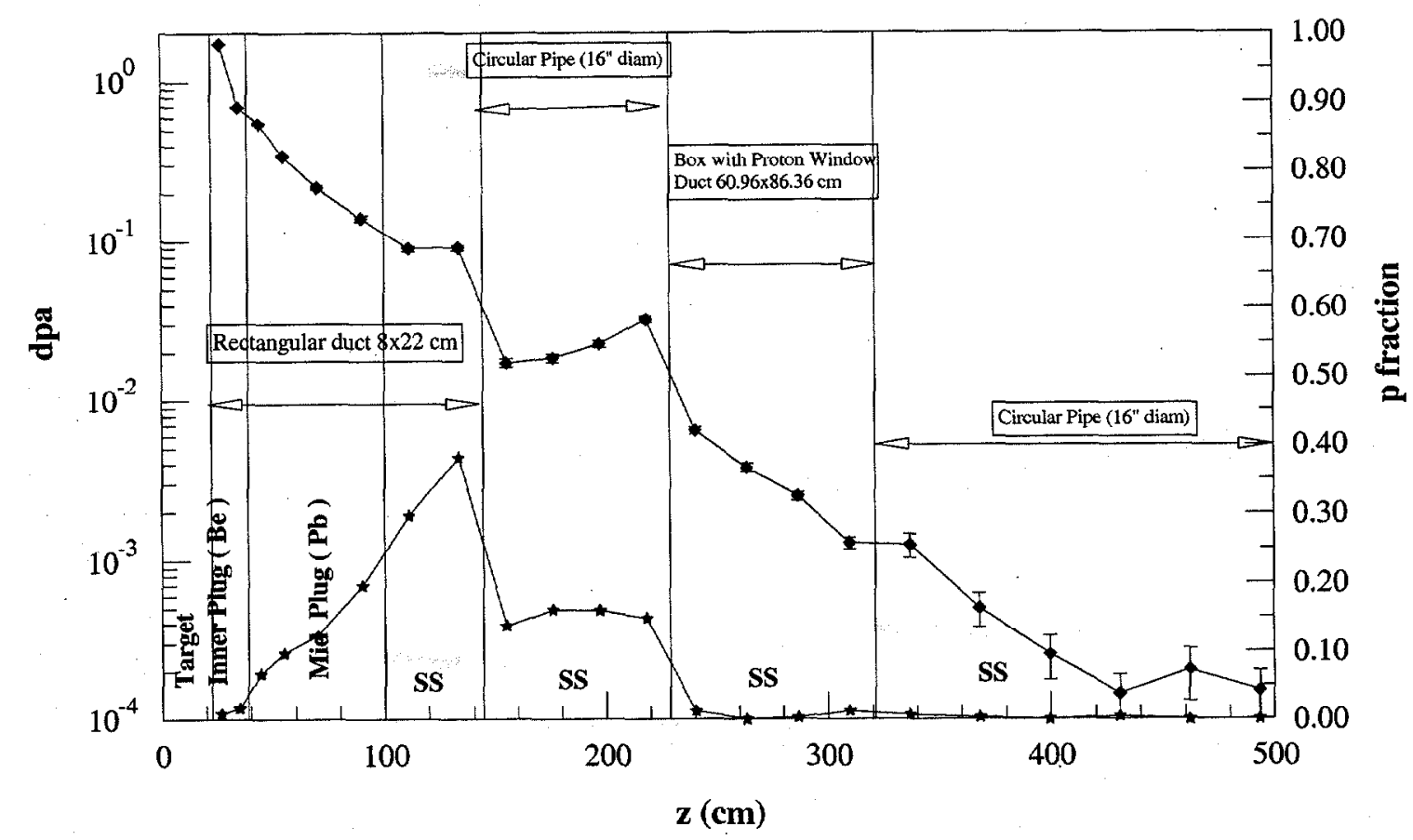

Figure 6: Total dpa and proton fractions (in stainless steel for 1 year at $2 \mathrm{~mA}$ ) for $2 \mathrm{~cm}$ thick rings along the path of the beam.

\section{Conclusions}

Detailed maps of the heating rates and the radiation damage were prepared to describe the conditions along the path of the proton beam of the Spallation Neutron Source project. The scattering of the protons by the window and the changes of the cross sections of the media along the path affect the distributions via the appearance of local maximums. About $94.4 \%$ of the protons arrive to the $\mathrm{Hg}$ target.

\section{References}

1.J. Johnson Target Neutronics for the Spallation Neutron Source, http://nas.cped.ornl.gov/pgm-sns.html 2.H.G. Hughes, et.al MCNPX for Neutron-Proton Transport, Mathematical and Computation Topical Meeting, American Nuclear Society, Sept 27-30, Madrid, Spain.

3. R.E. Prael and H. Lichtenstein User guide to LCS: The Lahet System, Los Alamos National Laboratory, LA-UR-89-3014 (Sept 1989).

4.T. A. Gabriel et al, CALOR98:A Monte Carlo Program Package for the Design and Analysis of Calorimetric System, Oak Ridge National Laboratory, ORNL-TM-11185.

5.J.F. Briemeister J.F., Editor MCNP: A General Monte Carlo N-Particle Transport Code, Los Alamos National Laboratory, LA-12625-M (March 1997).

6 F. Gallmeir, Private Communication, ORNL, April 20,2000.

7.M.H. Barnett, L.K. Mansur and L.A. Charlton Radiation Damage Analysis of the Spallation Neutron Source Target Vessel, Private Communication, ORNL, August 13,1999. 